\title{
Experimental Study on Desorption Characteristics of Anthracite in Positive Pressure Environments
}

\author{
Zheng GAO ${ }^{\mathrm{a}, 1}$ and Chong $\mathrm{CHEN}^{\mathrm{a}}$ \\ ${ }^{a}$ Pingdingshan Polytechnic College, Pingdingshan, Henan 46700 China
}

\begin{abstract}
In order to investigate the desorption characteristics of methane adsorption in coal under positive pressure conditions, methane adsorption and successive desorption experiments of anthracite coal under positive pressure conditions were conducted on the developed experimental equipment, and the experimental data were analyzed. In the process of desorption of coal samples with the same adsorption equilibrium pressure and the same pressure drop gradient, the phase desorption rate decreased with the increase of pressure, and the positive pressure environment had a significant inhibitory effect on the desorption of methane in coal.
\end{abstract}

Keywords. Anthracite, positive pressure environment, adsorption desorption, desorption lag

\section{Introduction}

Methane is one of the important companion organisms in the formation of coal, and the porous structure of coal matrix provides a good environment for methane attachment [1]. As the degree of coal metamorphism increases, there is a positive correlation between the amount of methane produced and the amount of methane adsorbed. The level of methane content in coal seams has a significant impact on coal mine safety, and at the same time, the exploitation of methane as a natural and clean energy source is receiving more and more attention from the society. The desorption of methane from coal is affected by many factors [2-5], and many scholars studied the adsorption laws of methane, and a lot of results have been obtained [6-9]. Wang Dengke [10] used the non-negative constrained least squares method to invert the methane adsorption and desorption data of granular coal and determined the exact range of gas diffusion coefficient D. Chen Xiangjun [11] studied the diffusive desorption process of gas-bearing coal under different negative pressure environments. and the results showed that the maximum increase is around 37.45\%; Ge Yanyan [12] conducted a study on The results showed that the maximum desorption and adsorption increased with the increase of negative pressure.

From the spatial distribution point of view, the coal body closer to the wellbore or the borehole is the first to generate a large pressure drop, and the pressure drop gradient

1 Zheng Gao, Pingdingshan Polytechnic College, Pingdingshan, Henan 46700 China; E-mail: 656516086@qq.com 
decreases with the increasing distance from the wellbore, so the methane in the coal is desorbed and transported to the wellbore gradually along with the pressure drop transfer process. Similarly, in the process of downhole coal sampling to determine the gas content, the coal samples taken from different types of samplers are also under positive pressure, and few experimental studies have been reported on the desorption characteristics of coal samples under positive pressure. Therefore, in order to investigate the desorption law of methane in coal under positive pressure, this study was conducted in the laboratory with the self-developed positive pressure desorption experimental system as the main body to investigate the desorption law of coal samples under positive pressure, in order to provide theoretical support for improving the efficiency of coal mine methane extraction and the accuracy of coal seam gas content determination.

\section{Experimental Platform and Method}

\subsection{Coal Sample Selection and Experimental Platform}

Anthracite coal from Jincheng mining area was used as the coal sample, which was made into a particle size of $1 \sim 3 \mathrm{~mm}$ and dried and sealed for backup. The industrial analysis parameters is shown in table 1 .

Table 1. Industrial analysis of coal samples.

\begin{tabular}{|c|c|c|c|c|c|c|}
\hline \multicolumn{3}{|c|}{ Parameters(\%) } & \multirow{2}{*}{$\operatorname{Density}\left(\mathrm{g} / \mathrm{cm}^{3}\right)$} & \multirow{2}{*}{ Porosity (\%) } & \multirow{3}{*}{$a$ value $\left(\mathrm{cm}^{3} / \mathrm{g} . \mathrm{r}\right)$} & \multirow{3}{*}{$\begin{array}{l}\mathrm{b} \text { value } \\
\left(\mathrm{MPa}^{-1} \cdot \mathrm{r}\right)\end{array}$} \\
\hline$M_{a d}$ & $A_{a d}$ & $V_{\text {daf }}$ & & & & \\
\hline 1.74 & 11.21 & 7.05 & 1.60 & 5.48 & & \\
\hline
\end{tabular}

In order to provide a positive pressure desorption environment, a set of experimental equipment was designed and processed, The schematic diagram is shown in figure 1.

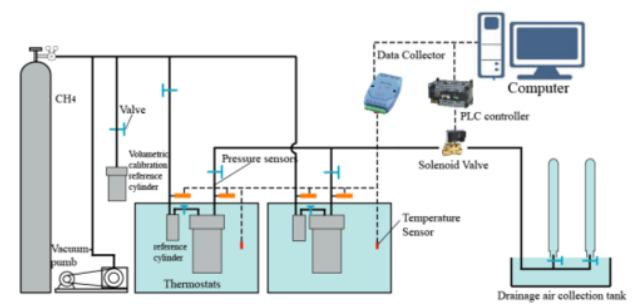

Figure 1. Schematic diagram of experimental device.

As shown in figure 1 , the accuracy of $0.10 \% \mathrm{FS}$ pressure sensor collects the pressure in the coal sample tank in real time and transmits the signal to the computer, which receives the pressure value and compares it with the preset pressure, and then controls the solenoid valve to open and close continuously and rapidly through the PLC controller. When the pressure inside the tank reaches the preset pressure value $\pm 5 \%$, the solenoid valve is closed, so that the ambient pressure inside the coal sample tank is always at the preset pressure and the methane gas flows out to the collection tank. 


\subsection{Experimental Steps}

Weigh $150 \mathrm{~g}$ of coal sample and put it into the coal sample jar. To calculate the actual desorption volume, use the volume calibration unit to calibrate the reference cylinder, the coal sample jar and the free volume in the jar after the coal sample is filled. (2) Vacuum degassing. The vacuum pump was used to evacuate the experimental system until the pressure remained constant within $4 \mathrm{~h}$ after the vacuum pump was turned off. (3) Gas injection and adsorption. Adjust the temperature to $30^{\circ} \mathrm{C}$ to inject high pressure methane gas into the reference cylinder, inject it into the coal sample tank through the reference cylinder, so that the coal can adsorb methane. Until the pressure in the tank no longer changes in $2 \mathrm{~h}$ as the adsorption equilibrium. (4) Positive pressure desorption. Set the desorption pressure, open the desorption valve to start desorption, desorption until the desorption gas is less than $2 \mathrm{ml}$ in $2 \mathrm{~h}$ is considered as the end of desorption, change the desorption pressure for the next desorption equilibrium pressure experiment. (5) Organize and analyze the experimental data, and quantify the adsorption and desorption as the volume under standard conditions.

\section{Analysis of Experimental Results}

\subsection{Analysis of the Results of Pressure Reduction Desorption}

The amount of gas injection and coal sample methane adsorption is calculated according to the following formula.

The total amount of methane gas injected into the reference cylinder is:

$$
Q_{C i}=\left(\frac{P_{1 \mathrm{i}}}{Z_{1 \mathrm{i}}}-\frac{P_{2 i}}{Z_{2 i}}\right) \frac{237.2 \times V_{0}}{\left(237.2+t_{1}\right) \times 0.101325}
$$

where, $Q_{c i}$ is the methane standard volume injected into the reference cylinder; $Z_{1 i}, Z_{2 i}$ are the compression coefficients of methane at $\mathrm{P}_{1 \mathrm{i}}, \mathrm{P}_{2 \mathrm{i}}$ pressures at temperature $\mathrm{t}_{1}$, respectively, dimensionless; $\mathrm{P}_{1 i}, \mathrm{P}_{2 \mathrm{i}}$ are the absolute pressures in the reference cylinder, $\mathrm{MPa}$; V0 is the volume of the reference cylinder, $\mathrm{cm}^{3} ; \mathrm{t}_{1}$ is the ambient temperature of the reference cylinder at the time of gas injection, ${ }^{\circ} \mathrm{C}$. The amount of free methane in the coal sample tank and reference cylinder after adsorption equilibrium is:

$$
Q_{d i}=\frac{273.2 \times P_{i} \times V_{d}}{\left(273.2+t_{1}\right) \times Z_{i} \times 0.101325}
$$

where: Qdi is the volume of free methane in the reference cylinder and coal sample tank, $\mathrm{cm}^{3} ; \mathrm{Vd}$ is the total free volume in sample tank and reference cylinder, $\mathrm{cm}^{3}$; $\mathrm{Pi}$ is the equilibrium pressure, $\mathrm{MPa}$. The amount of methane adsorbed per gram of coal is:

$$
\Delta Q=Q_{c i}-Q_{d i}, \quad Q_{x}=\frac{\Delta Q}{G_{\mathrm{m}}}
$$

where, $G_{m}$ is the weight of coal sample, g. Waiting for the methane adsorption equilibrium to be reached in the coal sample tank, table 2 shows the final coal sample 
methane adsorption equilibrium pressure and adsorption amount.

Table 2. Actual adsorption equilibrium pressure and methane adsorption capacity of coal sample.

\begin{tabular}{llllll}
\hline Adsorption equilibrium pressure $(\mathrm{MPa})$ & 1.0 & 1.5 & 2.1 & 2.8 & 3.0 \\
\hline Methane adsorption capacity $(\mathrm{ml} / \mathrm{g})$ & 17.91 & 21.32 & 24.15 & 25.63 & 26.03 \\
\hline
\end{tabular}

When the coal sample reaches adsorption equilibrium in each test, the desorption pressure is set to start the coal sample desorption test. The desorption pressure is set as follows: $0 \mathrm{MPa}, 0.2 \mathrm{Mpa}, 0.4 \mathrm{MPa}, 0.6 \mathrm{MPa}, 0.8 \mathrm{MPa}, 1 \mathrm{MPa}, 1.2 \mathrm{MPa}, 1.5 \mathrm{MPa}, 1.8 \mathrm{MPa}$, $2 \mathrm{MPa}, 2.5 \mathrm{MPa}$, and the coal samples with different adsorption equilibrium pressure are firstly lowered to the target desorption pressure nearest to the adsorption equilibrium pressure, and then the desorption is carried out one by one, and when the desorbed methane volume is less than $2 \mathrm{ml}$ within $2 \mathrm{~h}$, the desorption is considered to be finished. The desorption is considered to be finished when the amount of methane desorbed within $2 \mathrm{~h}$ is less than $2 \mathrm{ml}$. The amount of methane adsorbed in the desorbed coal sample is shown in table 3 .

Table 3. Methane adsorption capacity of coal sample after positive pressure desorption to different equilibrium pressure.

\begin{tabular}{|c|c|c|c|c|c|}
\hline \multirow{2}{*}{$\begin{array}{l}\text { Desorption } \\
\text { equilibrium } \\
\text { / }(\mathrm{MPa})\end{array}$} & \multicolumn{5}{|c|}{$\begin{array}{l}\text { Amount of methane adsorbed after desorption of coal sample at positive pressure } \\
\left(\mathrm{ml} \cdot \mathrm{g}^{-1}\right)\end{array}$} \\
\hline & $1.0 \mathrm{MPa}$ & $1.5 \mathrm{MPa}$ & $2.1 \mathrm{MPa}$ & $2.8 \mathrm{MPa}$ & 3.0MPa \\
\hline 2.5 & & & & 25.14 & 25.24 \\
\hline 2.0 & & & 23.89 & 24.02 & 24.27 \\
\hline 1.8 & & & 23.17 & 23.45 & 23.68 \\
\hline 1.5 & & 21.32 & 22.03 & 22.19 & 22.42 \\
\hline 1.2 & & 19.69 & 20.52 & 20.74 & 20.81 \\
\hline 1.0 & 17.91 & 18.38 & 18.94 & 19.31 & 19.23 \\
\hline 0.8 & 16.80 & 16.94 & 17.10 & 17.23 & 17.35 \\
\hline 0.6 & 14.42 & 14.54 & 14.57 & 15.05 & 15.07 \\
\hline 0.4 & 11.34 & 11.42 & 11.43 & 11.92 & 11.98 \\
\hline 0.2 & 7.22 & 7.27 & 7.24 & 7.44 & 7.46 \\
\hline 0 & 3.07 & 2.86 & 2.72 & 3.05 & 3.28 \\
\hline
\end{tabular}

As shown in table 3 and figure 2, the methane content adsorbed by coal samples with different initial adsorption equilibrium pressures showed an overall decreasing trend at different desorption equilibrium pressures after desorption by successive pressure reduction processes. After analyzing the experimental data, it was found that the differences between the maximum and minimum adsorption amounts at the same pressure were $0.11 \mathrm{ml} / \mathrm{g}, 0.39 \mathrm{ml} / \mathrm{g}, 0.51 \mathrm{ml} / \mathrm{g}, 0.71 \mathrm{ml} / \mathrm{g}, 1.12 \mathrm{ml} / \mathrm{g}, 0.85 \mathrm{ml} / \mathrm{g}, 0.55$ $\mathrm{ml} / \mathrm{g}, 0.65 \mathrm{ml} / \mathrm{g}$, and $0.65 \mathrm{ml} / \mathrm{g}$, respectively, after the desorption from high to low descending pressure to different pressures and reaching the adsorption equilibrium. $\mathrm{g}-1$, $0.65 \mathrm{ml} / \mathrm{g}, 0.65 \mathrm{ml} / \mathrm{g}, 0.24 \mathrm{ml} / \mathrm{g}, 0.21 \mathrm{ml} / \mathrm{g}$, as shown in figure 3 , with the increase of pressure, the difference between the maximum and minimum values of methane adsorption after desorption tends to increase first and then decrease, and the maximum point of the difference appears at the pressure of $1.2 \mathrm{MPa}$, and the difference is The maximum difference is $1.12 \mathrm{ml} / \mathrm{g}$, which is $5.69 \%$ relative to the smaller 
adsorption amount. The adsorption capacity of the experimental group with initial adsorption equilibrium pressure of $3 \mathrm{MPa}$ was $1.32 \mathrm{~mL} / \mathrm{g}$ higher than that of $1 \mathrm{MPa}$, and the relative difference was $7.3 \%$.

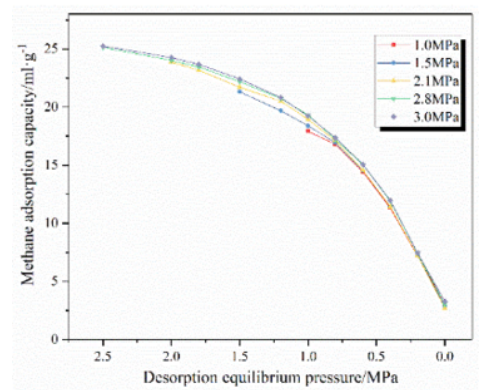

Figure 2. Methane adsorption after desorption

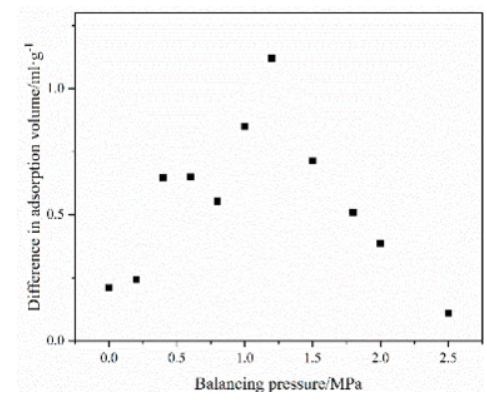

Figure 3. Difference of methane adsorption capacity after step-by-step depressurization and desorption reaching the same ambient pressure.

According to the results of adsorption after desorption, methane desorbed from the adsorbed state to the free state during the gradual decrease of ambient pressure at which the coal samples were subjected, and the content of methane adsorbed inside the coal samples with different initial adsorption equilibrium pressures differed to some extent after decreasing to the same adsorption equilibrium pressure, and the adsorbed amount showed a trend of increasing first and then decreasing. The methane already adsorbed was not all desorbed under the action of ambient pressure after the ambient pressure was reduced, and the ambient pressure had an inhibitory effect on the desorption of methane, and the adsorption and desorption processes of coal on methane were not completely reversible. During the process of will-pressure desorption, the experimental groups with higher adsorption pressure had similar adsorption equilibrium pressure and showed small differences during will-pressure desorption, and when the ambient pressure was reduced to near $1 \mathrm{MPa}$, the adsorption amount showed large differences after will-pressure desorption to the same ambient pressure due to the large difference in the initial adsorption equilibrium pressure of several groups of coal samples, and with the further decrease of ambient pressure, the adsorbed state methane in coal was driven by the pressure difference As the ambient pressure decreases further, the adsorbed methane in coal gradually diffuses outward driven by the pressure difference, and the adsorbed amount tends to be similar, and when the ambient pressure drops to atmospheric pressure, the adsorbed methane in several groups of coal samples tends to be equal.

\subsection{Analysis of the Pressure Reduction Desorption Process}

First, set the target desorption pressure and release the free gas in the coal sample tank into the gas bag, and then the desorption pipeline was connected to the gas collection tank, so that the desorbed gas entered the gas collection tank and recorded, and the real-time desorption amount of coal sample desorption process could be obtained. Figure 4 shows the desorption process of initial equilibrium pressure of $3 \mathrm{MPa}$, methane from 2.0 $\mathrm{MPa}$ to $1.8 \mathrm{MPa}, 1.0 \mathrm{MPa}$ to $0.8 \mathrm{MPa}$ and $0.2 \mathrm{MPa}$ to $0 \mathrm{MPa}$. 


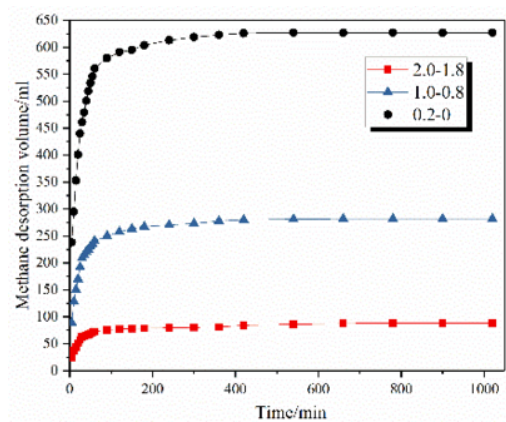

Figure 4. Desorption process at different pressure stages.

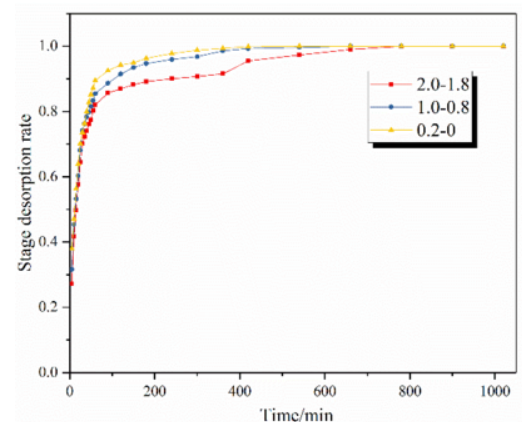

Figure 5. Desorption rate at different pressures.

To further explore the law of methane desorption in coal samples with the same pressure drop gradient in different pressure intervals under positive pressure environment, the $Q x$ is introduced.

$$
Q_{x}=\frac{Q_{t}}{Q_{p}} \times 100 \%
$$

where: $\mathrm{Q}_{\mathrm{x}}$ is the methane desorption rate at a certain moment in any pressure drop interval, dimensionless; $\mathrm{Q}_{\mathrm{t}}$ is the methane volume at moment $\mathrm{t}$ under a specific ambient pressure, $\mathrm{ml} / \mathrm{g} ; \mathrm{Q}_{\mathrm{p}}$ is the total amount of methane gas desorbed from coal sample when the sample reaches adsorption equilibrium under a specific ambient pressure, $\mathrm{ml} / \mathrm{g}$.

Figure 5 shows the phase desorption rates within the three stages of pressure drop desorption from 2.0 $\mathrm{MPa}$ to $1.8 \mathrm{MPa}, 1.0 \mathrm{MPa}$ to $0.8 \mathrm{MPa}$ and $0.2 \mathrm{MPa}$ to $0 \mathrm{Mpa}$ during the successive pressure drop desorption of coal samples with an initial adsorption equilibrium pressure of $3 \mathrm{MPa}$.

Figure 5 shows the desorption process of coal samples with initial adsorption equilibrium pressure of $3 \mathrm{MPa}$ at $2.0 \mathrm{MPa}-1.8 \mathrm{MPa}, 1.0 \mathrm{MPa}-0.8 \mathrm{MPa}$, and $0.2 \mathrm{MPa}-0$ $\mathrm{Mpa}$, and analysis of the images and data shows that in the three stages of pressure drop desorption, the desorption degree grows rapidly in the initial stage of desorption, and the stage desorption degree reaches $80 \%$ at $1 \mathrm{~h}$ of desorption for all three different pressure drop stages. After $1 \mathrm{~h}$, the rate of methane desorption gradually decreases significantly, and the rate of increase of the stage desorption rate also decreases with the increase of time. At the same moment, the desorption rates of three different desorption pressure stages from high to low are: $0.2 \mathrm{MPa}-0 \mathrm{Mpa}, 1.0 \mathrm{MPa}-0.8 \mathrm{MPa}$, $2.0 \mathrm{MPa}-1.8 \mathrm{Mpa}$, and the time taken to reach the adsorption-desorption equilibrium is $540 \mathrm{~min}$, 660min, 780min respectively, which shows that the ambient pressure has an inhibitory effect on the desorption of adsorbed methane in coal, making the methane The second desorption rate was accelerated after $6 \mathrm{~h}$ and $5 \mathrm{~h}$ of desorption in the experimental groups of $2.0 \mathrm{MPa}-1.8 \mathrm{Mpa}$ and $1.0 \mathrm{MPa}-0.8 \mathrm{Mpa}$, respectively, and then the desorption rate gradually decreased until the adsorption equilibrium was reached, while this phenomenon did not occur in the desorption at atmospheric pressure.

Therefore, by analyzing the desorption process at different pressure drop stages, it can be concluded that the positive pressure environment has an inhibitory effect on the desorption of methane from coal, unlike the atmospheric pressure desorption, which 
causes a hysteresis in the desorption of methane, and the hysteresis in the desorption is more obvious for coal at higher ambient pressure.

\section{Conclusion}

(1) For the same equilibrium pressure coal sample, the volume of gas desorbed at the high pressure stage was lower than that at the low pressure stage in the process of successive descending desorption, and the time required to reach the adsorption equilibrium was relatively shorter under the same pressure drop gradient.

(2) The positive pressure environment has an obvious inhibitory effect on the desorption of methane from coal, which makes the desorption of methane under positive pressure environment appear hysteresis, and the higher the ambient pressure, the more obvious the hysteresis.

(3) Because of the extremely long time required to reach the equilibrium of methane adsorption in large coal samples, granular coal was used as the experimental coal sample in this experiment, and in the subsequent experiments, column coal or large coal samples will be used for the experiments to be closer to the actual situation.

\section{References}

[1] Li XC, Li ZB, Zhang L. Pore structure characterization of various rank coals and its effect on gas desorption and diffusion. Journal of China Coal Society. 2019 Sep; 44(S1): 142-156.

[2] Li QS, Li GH, Wang EY. Experimental study on gas diffusion characteristics of granular coal with different particle sizes based on classical diffusion model. Journal of Safety Science and Technology. 2018 Sep; 14(9): 44-49.

[3] Nie BS, Liu XF, Guo JH. Effect of moisture on gas desorption and diffusion in coal mass. Journal of China University of Mining \& Technology. 2015 Sep;44(5): 781-787.

[4] Yang X, Zhang JY, Wang GD. Experimental study of the influence of gas pressure on the gas diffusion in coal. Journal of China University of Mining \& Technology. 2019 May; 48(3): 503-510, 519.

[5] Zhang HT, Hao YS, Wei JP. Study on characteristic parameters of particulate coal gas desorption and diffusion under negative pressure environment. Safety in Coal Mines. 2020 Oct; 51(10): 191-195.

[6] Liu YW, Liu MJ. Effect of particle size on difference of gas desorption and diffusion between soft coal and hard coal. Journal of China Coal Society. 2015 Mar; 40(3): 579-587.

[7] $\mathrm{Xu} \mathrm{LH}$, Jiang CL. Study on relation between coal's volatility and initial speed of methane emission. safety in coal mines. 2011 July; 42(7): 21-22, 27.

[8] Yang Y. Study on influence of temperature on initial expansion energy of released gas under constant pressure condition. Coal Technology. 2020 Dec; 39(12): 115-117.

[9] $\mathrm{Xu} \mathrm{HG}$, Liu WJ. Study on temperature change characteristics of coal gas adsorption-desorption process based on infrared measurement. Coal Mine Modernization. Jan; 2021(1): 124-128.

[10] Wang DK, Wang HL, Wei JP. Multi-diffusion coefficient model and diffusion parameter inversion of gas desorption for coal particles. Journal of Safety Science and Technology. 2016 July; 12(7): 10-15.

[11] Chen XJ, Duan ZP, Liu Y. Experiment study on diffusion features of gassy coal under negative pressure environment. Coal Science and Technology. 2016 June; 44(6): 106-110, 133.

[12] Ge YY, Qin Y, Fu XH. Comparative experimental study of atmospheric pressure desorption and methane pressure desorption among coal samples of different particle sizes. Journal of China University of Mining \& Technology. 2015 Mar; 44(4): 673-678. 